\title{
PELATIHAN MEDIA PEMBELAJARAN KEPADA GURU-GURU YAYASAN PENDIDIKAN MUHAMMAD SYATIR AL-GHAZALI TANGERANG SELATAN
}

Faradiba $^{1}$, Taat Guswantoro ${ }^{2}$, Septina Severina Lumbantobing ${ }^{3}$, Nya Daniaty Malau $^{4}$

1,2,3,4 Universitas Kristen Indonesia, Jakarta, Indonesia

faradiba@uki.ac.id; taat.guswantoro@uki.ac.id; septina.lumbantobing@uki.ac.id; malaunyadaniaty@gmail.com

\begin{abstract}
Abstrak
Pemanfaatan media pembelajaran digunakan sebagai alat penunjang yang dapat digunakan dalam proses belajar mengajar di sekolah. Media pembelajaran dapat menjadi solusi dalam mengatasi permasalahan pembelajaran. Tujuan dari kegiatan ini adalah: 1) Memberikan pengetahuan teoritis kepada guru-guru TK Islam Al-Ghazali Tangerang Selatan tentang pentingnya penggunaan media pembelajaran sains di TK, 2) Melatih guru-guru TK Islam Al-Ghazali Tangerang Selatan menggunakan media sains sederhana sebagai penunjang pembelajaran sains untuk anak TK. 3) Melatih guru TK Islam Al-Ghazali Tangerang Selatan membuat media sains sederhana. Kegiatan pengabdian kepada masyarakat dilakukan di TK Islam Al-Ghazali Tangerang Selatan. Hasil dari kegiatan pengabdian kepada masyarakat ini adalah guru-guru sangat senang dengan diadakannya pelatihan penggunaan media pembelajaran. Selain itu pengetahuan guru-guru TK juga meningkat yang dilihat dengan peningkatan kreatifitas guru dalam menciptakan media pembelajaran sains sederhana. Hasil praktik mengajar dan penggunaan media oleh guru-guru TK menunjukkan hasil yang baik, dilihat dari cara penyajian materi dan cara mengajar guru dalam membelajarkan sains juga meningkat.
\end{abstract}

Kata Kunci: Media Pembelajaran Sains, Guru, Taman Kanak Kanak.

\section{Abstract}

The use of learning media as a supporting tool in the teaching and learning process in class. Learning media can be a solution to overcome learning problems. The 
objectives of this activity are: 1) Providing theoretical knowledge the teachers of AlGhazali Islamic Kindergarten about the importance of using science learning media,

2) Training the teachers of Al-Ghazali Islamic Kindergarten using learning media as a support science learning for kindergarten. 3) Training the teachers of Al-Ghazali Islamic Kindergarten in South Tangerang makes media science. Location of this activity at the Al-Ghazali Islamic Kindergarten in South Tangerang. The results of the activities are that teachers are very happy with the training on the use of learning media. Besides that, the knowledge of teachers increases which can be seen from the increase in creativity from the teacher in creating simple science learning media. The results of teaching practices by teachers showed good results. It can be seen from the presentation and how to teach in learning science is increase.

Keywords : Science Learning Media, Teacher, Kindergarten.

\section{PENDAHULUAN}

Perkembangan jaman yang pesat ditandai dengan semakin beragamnya hasil produk teknologi. Kebutuhan akan alat yang memudahkan komunikasi, interaksi atau penyelesaian pekerjaan merupakan salah satu bentuk sulitnya kehdupan pada masa kini lepas dari kebutuhan hasil teknologi. Penggunaan teknologi yang meluas juga membawa pengaruh pada anak usia dini. (Wardhani, 2016).

Untuk meningkatkan kualitas pendidikan maka guru memegang peranan yang sangat penting, dimana kemampuan guru di dalam memberikan pelajaran merupakan landasan dalam mencapai sukses mengajar, terutama dalam hal meningkatkan hasil belajar siswa (Manambing 2018). Guru sebagai fasilitator dalam kegiatan belajar mengajar dituntut agar mampu menggunakan alat-alat yang disediakan sekolah dan dapat mengembangkan bahan ajar dalam bentuk media yang menarik dan interaktif. Oleh karena itu, guru diharapkan dapat berkreasi menggunakan dan membuat sendiri media pembelajaran yang dapat menarik perhatian siswa dan 
menjadikan belajar jadi lebih hidup (Sukamti, 2018).

Menurut Don Campbell dalam Fahruddin.dkk (2017) bahwa anak pada tahun awal perkembangan, otak anak dipengaruhi oleh keadaan atau situasi di sekelilingnya. Anak memasuki tingkat pendidikan selanjutnya juga tidak terlepas dari pengalaman awal yang sudah melekat dalam diri anak yang diperoleh dari hasil melihat orang tuanya, karenanya orang tua merupakan pendidik utama dalam keluarga. Apa yang dilakukan anak sebagian besar merupakan perilaku imitasi orang tuanya.

Perkembangan kecerdasan pada masa 4-6 tahun mengalami peningkatan dari $50 \%$ menjadi $80 \%$. Selanjutnya kapasitas kecerdasan anak akan mencapai $100 \%$ pada usia 18 tahun. Oleh sebab itu dibutuhkan kondisi dan stimulasi yang sesuai dengan kebutuhan anak agar pertumbuhan dan perkembangan anak tercapai secara optimal. Peran pendidik (orang tua, guru dan orang dewasa lain) sangat diperlukan dalam upaya pengembangan potensi anak usia 4-6 tahun. Upaya pengembangan tersebut dapat dilakukan melalui kegiatan bermain sambil belajar. Anak yang bermain mempunyai kesempatan untuk bereksplorasi, menemukan, mengekspresikan perasaan, berkreasi, dan belajar secara menyenangkan. Disamping itu melalui bermain membantu anak mengenal dirinya sendiri, orang lain dan lingkungan (Yulianti dan Dewanti, 2015).

Metode pembelajaran yang tepat dapat mengahasilkan pengetahuan yang maksimal terhadap peserta didik. Terutama pada peserta didik yang notabenenya merupakan anak dibawah umur yang baru menerima ilmu pengetahuan dari sekolah. Model pembelajaran perlu dirancang semenarik mungkin guna meningkatkan semangat belajar para siswa dan juga menambah kepercayaan orang tua terhadap institusi penyelenggara pendidikan. Menurut data dari BPS, nilai Angka Partisipasi Kasar (APK) pada jenjang Pendidikan Anak Usia Dini (PAUD) Tahun 2016 pada wilayah perkotaan dan pedesaan masing-masing sebesar 36,96 persen dan 32,29 persen. Angka ini relatif kecil jika melihat pentingnya fungsi pendidikan anak usia dini sebagai pondasi awal dalam menggali ilmu sampai jenjang universitas. Faktor-faktor penyebab rendahnya APK PAUD antara lain karena faktor ekonomi keluarga, masih dianggap 
kurang penting oleh suatu rumah tangga, pendidikan yang didapat melalui PAUD dapat dilakukan di rumah oleh orang tua, PAUD difokuskan hanya bermain, sedangkan untuk bekal menuju SD (calistung) masih kurang, dan sebagainya.

Melalui informasi diatas diperlukan suatu aksi untuk meningkatkan pengetahuan peserta didik melalui peningkatan kapasitas guru sekaligus simulasi kepada peserta didik melalui benda-benda yang ada di sekitar.

\section{METODE}

Dalam melaksanakan kegiatan pengabdian kepada masyarakat, sasaran kegiatan adalah guru Taman Kanak Kanak Yayasan Pendidikan Muhammad Syatir AI-Ghazali. Metode kegiatan pengabdian kepada masyarakat yang dilakukan sebagai berikut:

1. Metode ceramah.

Metode ini dilakukan untuk memberi penjelasan tentang pentingnya pembelajaran berbasis media untuk anak. Tim instruktur menyiapkan beberapa materi terkait penjelasan pentingnya penggunaan media pembelajaran. Selain itu tim juga telah menyiapkan beberapa media pembelajaran. Adapun media pembelajaran berupa media pembelajaran sains.

2. Metode praktik mengajar dan penggunaan media.

Selain memberikan penjelasan melalui ceramah dan memberikan materi, instruktur juga memandu dan mendampingi guru-guru dalam melakukan praktik mengajar dan penggunaan media pembelajaran. Pada tahap ini tiap guru wajib mempraktekkan media pembelajaran yang telah disiapkan oleh instruktur.

3. Metode tanya jawab dan diskusi.

Setelah sesi pemberian materi dan praktik, guru-guru diberikan kesempatan untuk diskusi. Pada tahap ini peserta dibagi menjadi 3 kelompok dan masing masing kelompok didampingi oleh tiap instruktur.

\section{HASIL DAN PEMBAHASAN}

Kegiatan pelatihan media pembelajaran ini diikuti oleh 7 peserta. Pelaksanaan kegiatan pelatihan dilakukan pada tanggal 6 Desember 2018 di TK Islam Al-Ghazali Tangerang Selatan. Secara umum kegiatan pelatihan media 
pembelajaran ini berjalan lancar. Kegiatan pelatihan tersebut bekerja sama dengan Sekolah Tinggi Theologi (STT) Moria Tangerang Selatan.

Kegiatan Pelatihan media pembelajaran dilakukan dengan menggunakan contoh media pembelajaran yang telah disiapkan sebelumnya oleh instruktur. Adapun media yang dipraktekkan adalah eksperimen sains yaitu sifat-sifat zat cair.

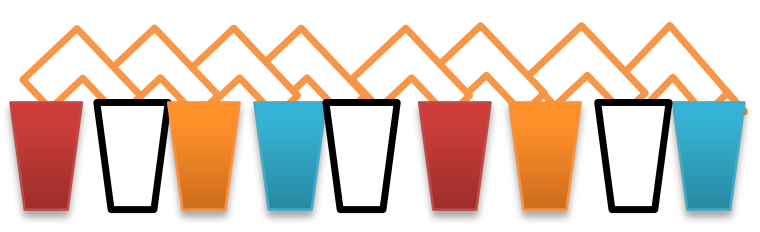

Gambar 1. Sketsa Media Pencampuran warna

Dari satu media pembelajaran ini bebebrapa penjelasan yang dapat kita berikan seperti:

- Ketika air dicampur dengan pewarna, maka air berubah warna. Hal ini membuktikan bahwa air dapat melarutkan zat.

- Ketika tisu dimasukkan ditiap gelas, tisu menjadi basah. hal ini membuktikan bahwa air dapat meresap.

- Ketika air dimasukkan ke sebuah wadah mangkuk atau botol maka air berubah bentuk mengukuti wadahnya.

- Pada gelas yang tadinya kosong setelah di masukkan tisu dan air meresap, maka gelas kosong terisi air. Hal ini membuktikan bahwa air mengalir dari tempat tinggi ke tempat yang rendah.

- Pada gelas yang kosong akan menghasilkan gelas yang berisi air dengan warna yang berbeda. Hal ini membukktikan bahwa pencampuran 2 warna dasar akan menghasilkan warna yang baru/ berbeda.

Secara keseluruhan kegiatan pelatihan yang dilakukan oleh tim pengabdian telah berjalan dengan baik dan lancar sesuai dengan rencana yang telah ditentukan. Dari kegiatan pelatihan tersebut menunjukkan respon positif guru dalam kegiatan pelatihan. Pada tahap awal dimana tim instruktur memaparkan materi pentingnya penggunaan media pembelajaran dalam proses belajar mengajar. Guru sangat tertarik dengan materi yang disampaikan oleh tim instruktur dan guru berpartisipasi aktif dalam setiap kegiatan pelatihan dengan bertanya kepada pemateri tentang materi yang kurang dipahami. Disamping itu tidak sedikit dari guru 
yang berdiskusi kepada instruktur dan memberikan pandangan yang lain mengenai media pembelajaran yang pernah guru terapkan di kelas.

Pada tahap kedua dimana instruktur mendemonstrasikan media sains yang telah disiapkan. Pada tahap ini peningkatan wawasan tentang media pembelajaran juga mengalami peningkatan yang ditunjukkan dengan antusiasme guruguru yang sangat senang dan sangat memperhatikan tim dalam menjelaskan dan mendemonstrasikan media pembelajaran. Selain itu setiap guru juga mencoba mempraktekkan media seperti yang yang telah diinstruksikan. Bahkan ada beberapa guru yang kreatif memodifikasi media untuk menghasilkan proses pembelajaran yang baru.

Pada tahap ketiga pada kegiatan pelatihan ini guru diajak diskusi satu sama lain dengan membuat kelompok kecil untuk dapat menyimpulkan hasil kegiatan yang telah dilakukan pada tahap satu dan tahap dua. Antusiasme guru pun tidak berkurang sma sekali. Hampir semua guru mengemukakan pendapatnya dan simpulannya berdasarkan apa yang telah dilakukan pada tahap sebelumnya. Pada hasil diskusi ini pula di peroleh banyak tanggapan beragam yang positif untuk kegiatan media pembelajaran tersebut. dari hasil wawancara guru, semua guru menginginkan kegiatan pelatihan diharapkan bisa dilakukan secara berkala sehingga kemampuan dan kreativitas guru-guru daalm proses belajar mengajar dapat meningkat dan berdampak positif pula kepada peningkatan capaian pembelajaran dari peserta didik.

Pada kegiatan pelatihan media pembelajaran ini juga terdapat beberapa faktor penghambat diantanya : (1) Waktu penelitian yang hanya sehari yang dimulai pukul 08.00 - 14.00 WIB tersebut dirasa belum maksimal karena adanya demonstrasi media pembelajaran yang dilakukan oleh setiap guru, sehingga guru belum bisa secara optimal mendayagunakan media pembelajaran tersebut. Maka dari itu perlu dilakukan pelatihan lanjutan dengan durasi waktu yang lebih panjang agar pelatihan media pembelajaran tersebut dapat lebih optimal dilakukan; (2) Media yang dibuat pada pelatihan ini hanya menggunakan satu media yaitu media sains saja, akan lebih baik lagi apabila tidak hanya media saja saja yang dipraktekkan dalam pelatihan ini tetapi media pembelajaran bahasa sangat 
penting untuk guru TK; (3) Peserta pelatihan media ini hanya berasal dari satu yayasan saja yaitu Yayasan Pendidikan Muhammad Syatir AlGhazali Tangerang Selatan. Sebaiknya untuk pelatihan selanjutnya peserta berasal dari beberapa yayasan/ sekolah sehingga lebih banyak informasi dan sharing informasi yang terjadi diantara kalangan guru TK.

Beberapa dokumentasi kegiatan selama pelatiha berlangsung diantaranya :

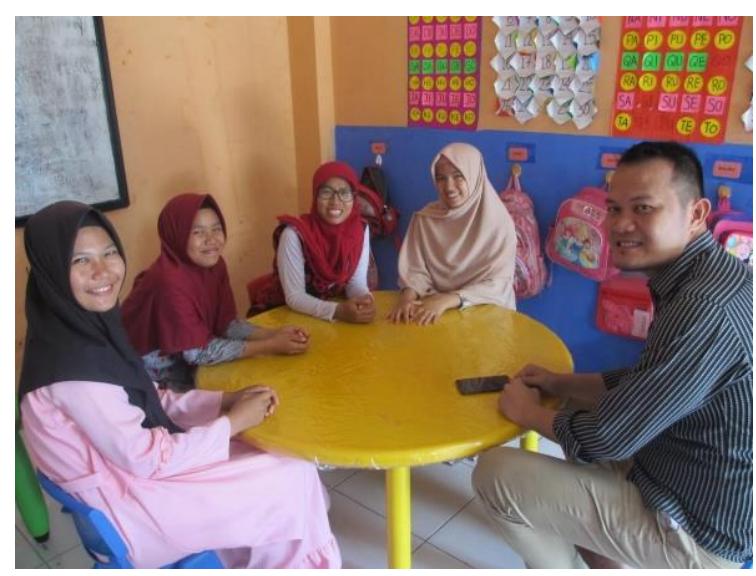

Gambar 2. Melakukan Diskusi dengan Guru

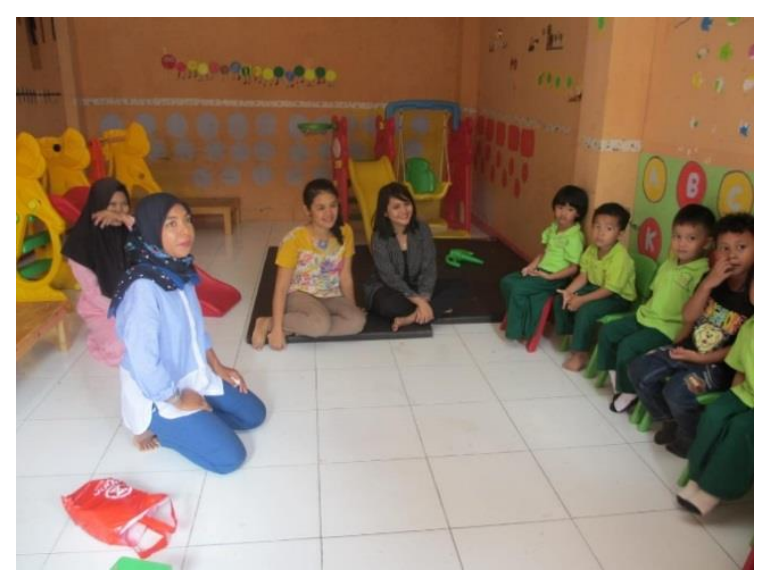

Gambar 3. Pengenalan Tim dengan Guru dan Murid

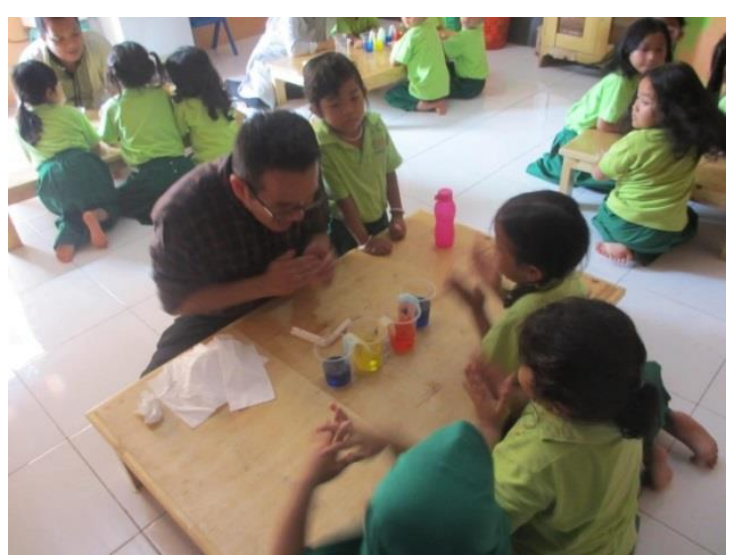

Gambar 4. Demonstrasi media pembelajaran kepada murid

\section{SIMPULAN}

Dari hasil kegiatan pengabdian masyarakat yang dilakukan, guru-guru sangat senang dengan diadakannya pelatihan penggunaan media pembelajaran. Selain itu pengetahuan guru-guru TK juga meningkat yang dilihat dengan peningkatan kreatifitas guru dalam menciptakan media pembelajaran sains sederhana.

Hasil praktik mengajar dan penggunaan media oleh guru-guru TK menunjukkan hasil yang baik, dilihat dari cara penyajian materi dan cara mengajar guru dalam membelajarkan sains juga meningkat. Diharapkan setelah selesainya kegiatan pengabdian ini, tetap diadakan pantauan tentang kemampuan guru- 
guru dalam pembuatan media pembelajaran dan jika memungkinkan waktu pelatihan dapat diperpanjang. Pelaksanaan ujicoba penggunaan media pembelajaran sains diperluas sehingga hasil yang diperoleh dapat digunakan sebagai acuan standar kelayakan media pembelajran sains yang cocok dalam pembelajaran murid Taman Kanak- Kanak.

\section{UCAPAN TERIMA KASIH}

Ucapan terima kasih kami sampaikan kepada :

1. Universitas Kristen Indonesia yang telah membiayai kegiatan pengabdian kepada masyarakat.

2. Yayasan

Pendidikan Muhammad Syatir Al-Ghazali yang telah memberikan kesempatan kepada tim untuk dapat melakukan pengabdian di TK Islam Al-Ghazali Tangerang Selatan.

3. Sekolah Tinggi Theologi (STT) Moria Tangerang Selatan sebagai mitra dalam menjalankan pengabdian kepada masyarakat di TK Islam Al-Ghazali Tangerang Selatan.

\section{REFERENSI}

Fahruddin, dkk. (2017). Efektifitas Parenting Dalam Peningkatan Proses Stimulasi Tumbuh Kembang Anak di PAUD/TK kota mataram. Laporan Penelitian PNBP Unram.

Manambing R, Domu I, \& Mangelep, N. (2018). Penerapan Pendekatan Pendidikan Matematika Realistik Indonesia Terhadap Hasil Belajar Siswa Materi Bentuk Aljabar, JSME MIPA UNIMA, Vol. 5 No. 2. Hal :

Sukamti, Untari E. (2018). Pelatihan Pembuatan Media pembelajaran dari Barang Bekas. Jurnal Abdimas Pedagogi. Vol. 1 No. 2 . Hal : 159-163

Wardhani W D L. (2016). Memperbaiki Keterampilan Komunikasi dalam Program Parenting. Jurnal Pengabdiam Masyarakat Ipteks. Vo. 2 No. 2 . Hal : 75-81

Yulianti D, Dewanti SS. (2015). Peningkatan Kompetensi Guru Taman Kanak-Kanak Kota Semarang dalam Membuat Alat Bermain Sains dari Limbah. 
Volume 1, Nomor 1, Tahun 2019 Hal 28 -36

Jurnal Rekayasa. Vol. 13 No.2

Hal : 160-166 